\title{
Review of: "Covid 19: How harm reduction advocates and the tobacco industry capitalised on the pandemic to promote nicotine"
}

\author{
Brad Rodu ${ }^{1}$ \\ 1 University of Louisville
}

\begin{abstract}
Potential competing interests: The author's research is supported by unrestricted grants from tobacco manufacturers to the University of Louisville and by the Kentucky Research Challenge Trust Fund. The sponsors had no knowledge of this work and therefore had no input or other influence in the design, analysis, interpretation, or in the preparation of and decision to submit the rapid response.
\end{abstract}

The recent article by Stéphane Horel and Ties Keyzer claimed that "the tobacco industry capitalised on the [covid 19] pandemic to promote nicotine" when "two preprints published in quick succession in April 2020... made headlines worldwide. They were also picked up by libertarian media outlets... The World Health Organization worried that decades of tobacco control could be undermined." (1)

Horel and Keyzer then stated: "It has since been roundly disproved that smoking protects against covid-19. Among other studies $(\underline{2}, \underline{3}, \underline{4})$ the OpenSafely dataset, based on the primary care records of 17.3 million adults in the UK, found that smoking, when adjusted for age and sex, was associated with a $14 \%$ increased chance of covid-19 related death (므.."

Horel and Keyzer implied that the four research citations (assigned different reference numbers here) "roundly disproved that smoking protects against covid-19." It is ironic that the article by Horel and Keyzer was published in BMJ under the topic of "Research Integrity," because their own research may not have reached the level readers deserve in a quality medical journal. In fact, a close look at their four studies, and others that they omit, roundly disproves their disproval claim.

Three of the four studies $(2, \underline{3}, \underline{4})$ cited by Horel and Keyzer report positive associations, but they need further clarification. For example, the first study did not employ rigorous diagnostic criteria: study participants used an app launched via radio, TV and social media in the UK to report covid-19 "symptoms" and "whether they thought that they already had COVID" (2). The second study found that smokers were 3.5 times more likely to have confirmed covid-19 (95\% confidence interval, $\mathrm{Cl}=2.4-6.1$ ) than never smokers, but this was only true for participants with low education (푸). However, the risk for highly educated smokers was not elevated at all. A longitudinal follow-up study found that current smokers had a slightly, but non statistically significant, elevated odds of confirmed covid-19 (minimally adjusted odds ratio $(A O R)=1.24, C l=0.85-1.24)(\underline{4})$. Finally, Horel and Keyzer carefully describe the OpenSafely study 
(ㄷ) as evidence, saying that current smoking, "when adjusted for age and sex, was associated with a $14 \%$ increased chance of covid-19 related death." True enough. But what they fail to mention is that, when the result was fully adjusted for confounding factors, the effect of current smoking became statistically significantly protective $(A O R=0.89, \mathrm{Cl}=0.82-0.97)$.

Horel and Keyzer also failed to accurately cite and acknowledge studies that have shown a protective effect of current smoking on covid-19 $(\underline{6}, \underline{7}, \underline{8})$. They mentioned such a study from China but didn't reference it, which is unfortunate because it was published in the New England Journal of Medicine (ㅁ). They also mentioned and cited a study from France ( $\mathbf{7})$, but characterized it only as published quickly and as the origin of media hype.

Horel and Keyzer completely omitted other studies, such as one involving veterans in the U.S., which found that smokers were much less likely to test positive for covid-19 than nonsmokers $(A O R=0.45, \mathrm{Cl}=0.35$ 0.57) (8). Another omission was a rapid evidence review of 28 observational studies finding that "Current data suggest that smokers in the community appear to be less likely to test positive for SARS-CoV-2 compared with never smokers," "Across 405 studies, recorded current but not past smoking prevalence was generally lower than national prevalence estimates. Current smokers were at reduced risk of testing positive for SARS-CoV-2 and former smokers were at increased risk of hospitalisation, disease severity and mortality compared with never smokers." (9) However, one omission by Horel and Keyzer is especially inexplicable, because the study was published by this journal (BMJ) (10). In that study smokers were significantly less likely than non-smokers to be diagnosed with COVID-19 and to be admitted to an intensive care unit (ICU), and the latter effect was dose-dependent. The adjusted hazard ratios for ICU admission was $0.26(\mathrm{Cl}=0.19-0.37)$ for light smokers and $0.07(\mathrm{Cl}=0.01-0.47)$ for heavy smokers.

In summary, there is substantial evidence that current smoking may be negatively associated with a covid19 diagnosis and its subsequent course, including death.

\section{Brad Rodu}

Professor of Medicine

Endowed Chair, Tobacco Harm Reduction Research

University of Louisville

References

1. Horel S, Keyzer T. Covid 19: How harm reduction advocates and the tobacco industry capitalised on the pandemic to promote nicotine. BMJ 2021. 373 doi: https://doi.org/10.1136/bmj.n1303 (Published 02 June 2021) 
2. Hopkinson NS, Rossi N, El-Sayed Moustafa J, et al. Current smoking and COVID-19 risk: results from a population symptom app in over 2.4 million people. Thorax 2021. https://doi:10.1136/thoraxjnl-2020$\underline{216422}$

3. Jackson SE, Brown J, Shahab L, et al. COVID-19, smoking and inequalities: a study of 53002 adults in the UK. Tob Control 2020. https://doi:10.1136/tobaccocontrol-2020-055933

4. Holt H, Talaei M, Greenig M, et al. Risk factors for developing COVID-19: a population-based longitudinal study (COVIDENCE UK). MedRxiv 2021 [preprint]. https://doi:10.1101/2021.03.27.21254452

5. Williamson EJ, Walker AJ, Bhaskaran K, et al. Factors associated with COVID-19-related death using OpenSAFELY. Nature 2020;584:430-6. https://doi:10.1038/s41586-020-2521-4 pmid:32640463

6. Guan WJ, Ni Z, Hu Y, et al. Clinical characteristics of coronavirus disease 2019 in China. N Engl J Med 2020 382, 1708-1720. https://DOI:10.1056/NEJMoa2002032

7. Miyara M, Tubach F, Pourcher V, et al. Low rate of daily active tobacco smoking in patients with symptomatic COVID-19. Qeios. 9 May 2020. https://www.qeios.com/read/WPP19W.4

8. Rentsch CT, Kidwai-Khan F, Tate JP, et al. Covid-19 testing, hospital admission, and intensive care among 2,026,227 United States veterans aged 54-75 years. MedRxiv 2020

https://doi.org/10.1101/2020.04.09.20059964.

9. Simons D, Shahab L, Brown J, et al. The association of smoking status with SARS-CoV-2 infection, hospitalisation and mortality from COVID-19: A living rapid evidence review with Bayesian meta-analyses (version 11). Qeios 2021. https://doi:10.32388/UJR2AW.13

10. Hippisley-Cox J, Young D, Coupland C, et al. Risk of severe COVID-19 disease with ACE inhibitors and angiotensin receptor blockers: cohort study including 8.3 million people. BMJ Volume 106, Issue 19, 2020 https://heart.bmj.com/content/106/19/1503 